\title{
Multi-hazard climate risk projections for the United States
}

\author{
Binita KC ${ }^{1,4}$. J. M. Shepherd ${ }^{2} \cdot$ Anthony W. King $^{1} \cdot$ Cassandra Johnson Gaither $^{3}$
}

Received: 18 April 2019 / Accepted: 17 October 2020 / Published online: 1 November 2020

(c) The Author(s) 2020

\begin{abstract}
Climate risk is a consequence of climate hazards, exposure, and the vulnerability (IPCC 2014). Here, we assess future (2040-2049) climate risk for the entire contiguous US at the county level with a novel climate risk index integrating multiple hazards, exposures and vulnerabilities. Future, weather and climate hazards are characterized as frequency of heat wave, cold spells, dryer, and heavy precipitation events along with anomalies of temperature and precipitation using high resolution $(4 \mathrm{~km})$ downscaled climate projections. Exposure is characterized by projections of population, infrastructure, and built surfaces prone to multiple hazards including sea level rise and storm surges. Vulnerability is characterized by projections of demographic groups most sensitive to climate hazards. We found Florida, California, the central Gulf Coast, and North Atlantic at high climate risk in the future. However, the contributions to this risk vary regionally. Florida is projected to be equally hard hit by the three components of climate risk. The coastal counties in the Gulf states of Louisiana, Texas, Mississippi and Alabama are at high climate risk due to high exposure and hazard. High exposure and vulnerability drive high climate risk in California counties. This approach can guide planners in targeting counties at most risk and where adaptation strategies to reduce exposure or protect vulnerable populations might be best applied.
\end{abstract}

Keywords Climate risk $\cdot$ Projection $\cdot$ Sea level rise $\cdot$ Hazards $\cdot$ Exposure $\cdot$ Vulnerability

Electronic supplementary material The online version of this article (https://doi.org/10.1007/s1106 9-020-04385-y) contains supplementary material, which is available to authorized users.

Binita KC

binita.kc@nasa.gov

1 Environmental Sciences Division, Oak Ridge National Laboratory, One Bethel Valley Road, Oak Ridge, TN 37830, USA

2 Department of Geography, The University of Georgia, 210 Field Street, Athens, GA 30602, USA

3 USDA Forest Service, 320 Green Street, Athens, GA 30602-2044, USA

4 ADNET Systems Inc/ NASA Goddard Space Flight Center, Code 610.2 Blg 32, Greenbelt, MD 20771, USA 


\section{Introduction}

The IPCC's fifth assessment report (IPCC 2014) stresses the importance of three components in a climate risk model useful to policy makers: weather and climate hazards, exposure of people and assets to those hazards and the vulnerability of those exposed assets and people (Fig. 1). Single weather and climate events have their own risks (Hauer et al. 2016; Jones et al. 2015; Baum et al. 2008), but most locations are exposed to more than one type of extreme events. Each hazard is uniquely characterized by its impacts and consequences. For example, disaster events such as drought/heat wave and tropical storms are the leading cause of human casualties, but the economic losses from tropical storm damage far outweigh the loss caused by direct drought and heat wave events. NOAA's billion-dollar disaster report (NOAA 2019) shows that in the United States, from 1980 to 2019 drought/heat waves alone claimed around 3000 lives, and tropical cyclones similarly claimed 6500 lives, whereas the economic loss from these events accounted for 15 and $55 \%$ of the cumulative loss from all major disaster events, respectively, during this period.

In addition to the extreme events, changes in mean state (climate) can also contribute to risk. Ecosystems, for example, are adapted to a certain range of temperature and precipitation. A slight change in temperature and/or precipitation over a period of time can result in profound ecological impacts on ecosystem services. For example, change in precipitation affects fish production due to changes in runoff (Rijnsdorp et al. 2009). Similarly, biodiversity loss and decline in fish stock are positively correlated to change in mean temperature (Nunez et al. 2019; Tu et al. 2018). For instance, changes in mean temperature and precipitation impact species composition and timber yield of forests (Rasche et al. 2013). Rising temperatures lead to glacier melting, which is evident in the U.S.'s Glacier National Park and glacier watershed in Pacific Northwest (Hall and Fagre 2003; Frans et al. 2018). In the Midwest, warming of streams, rivers and lakes potentially affects cold-water fish, such

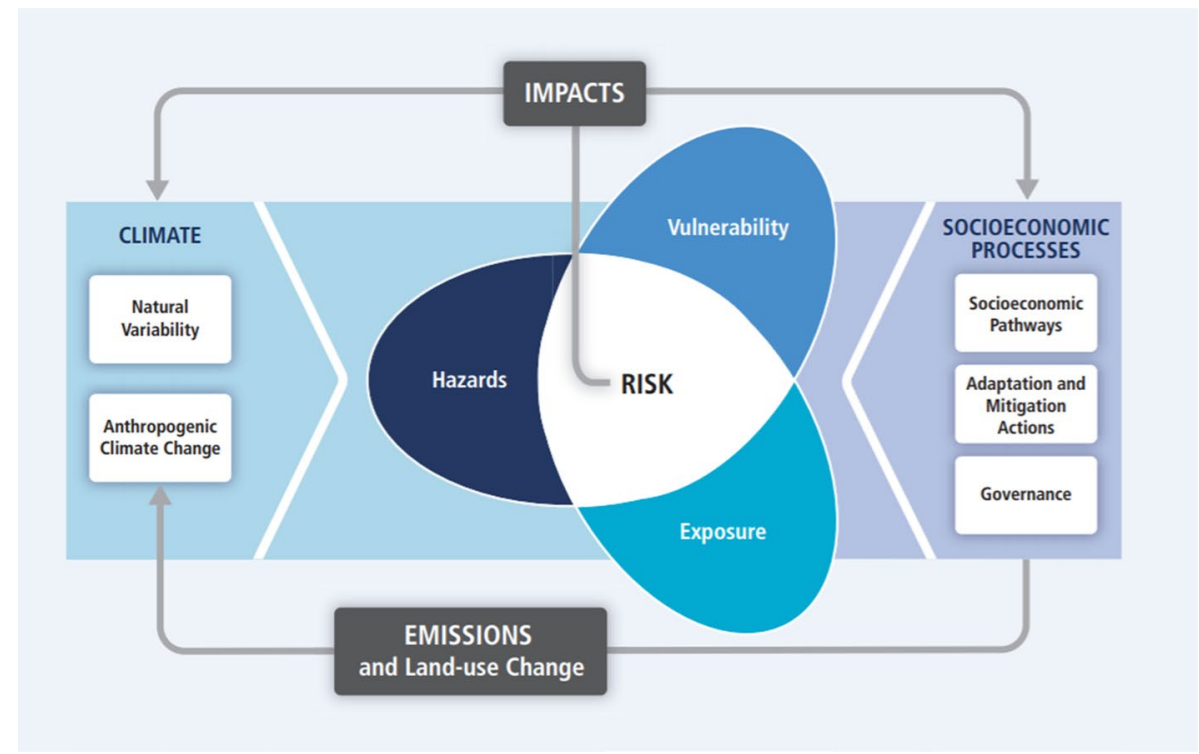

Fig. 1 Climate-elated risk resulting from synergistic interaction of weather and climate hazards, vulnerability, and exposure of human and environment systems ( Source: IPCC 2014) 
as economically important trout, through impacts on reproduction and food availability (Wenger et al. 2011; Williams et al. 2015). The abundance of fish species impact the population that depend on fishing for their livelihood (Kuczynski et al. 2017). When multiple hazards co-occur in time or space, the risk is exacerbated. Therefore, rather than focusing on the risk of a single hazard type, a multi-hazard framework can better serve a comprehensive understanding of future climate risk.

Multiple sectors of society are exposed to climate risks. Urban areas, for example, are highly susceptible to multiple hazards due to higher population concentrations, infrastructure, and other investments (Jones et al. 2015). In addition to temperature and precipitation changes, coastal areas must also contend with sea level rise and increased frequencies of storm surges (Hauer et al. 2016; Nicholls et al. 2008; Sweet et al. 2017a, b). Importantly, some socio-demographic groups are more vulnerable than others-for instance, the youngest and oldest age groups (i.e., those under $5 \mathrm{y}$ of age and those over $70 \mathrm{y}$ of age), natural resource-dependent populations (i.e., economies dependent on agriculture, forestry, fishery), and lower wealth groups bear a disproportionate burden of climate hazards (Emrich and Cutter 2011; Karl et al. 2008; Shepherd and KC 2015; Reams et al. 2012). Responding to the needs and challenges faced by the multiplicity of societal actors affected by a changing climate is the task at hand for governments at varying levels.

We project climate risk in the mid-century (2040-2049) for counties of the contiguous United States, integrating multiple hazards, exposures, and vulnerabilities. The weather and climate hazards are characterized by anomalies in mean temperature and precipitation coupled with extreme precipitation days, heat waves, cold spells, and wet-dry conditions for the ten-year period (KC et al. 2015). The weather and climate hazards are calculated for RCP 8.5, a "high" emission scenario, using climate projections from ten global climate models in the World Research Climate Program's CMIP5 archive dynamically downscaled to $4 \mathrm{~km}$ resolution (Ashfaq et al. 2016) with a historic baseline period of 1981-2010. The "high" emission scenario was selected based on the assumption that these nominally "high" scenarios are unlikely to significantly diverge from "business-as-usual" before 2050 (Jay et al. 2018). We quantify exposure with projections of impervious surface area, population, and housing density in the 2040s, along with roads and housing exposed to $0.6 \mathrm{~m}$ ( 2 feet) of sea level rise and storm surge in the coastal counties. Vulnerability is the combination of socioeconomic projections of elderly and infant populations, natural resourcedependent populations of farming, forestry, and fishery, and personal income per capita. These individual quantifications are first transformed into normalized (0-1) indices of hazard, exposure and vulnerability and combined by multiplying the three components. This is the first time the IPCC (IPCC 2014) risk framework has been applied to a multi-hazard, multi-exposure, multi-vulnerability characterization of future climate risk for the entire contiguous US at the county level.

\section{Data and methods}

The climate risk projection is performed for the mid-century (2040-2049), the 2040s, and the dimensions of risk are explored in different physiographic domains in the conterminous United States. The 2040s were chosen because there are large uncertainties associated with the demographic projection toward the end of the century, and our primary focus is to provide a near-term climate risk that could be useful to planners and stakeholders. The IPCC (2014) model of risk (a function of hazards, exposure, and vulnerability) is adopted 
to quantify climate risk. Hazards are the climate-related physical events and changes in mean temperature and precipitation. Exposure is the presence of people, livelihoods, and infrastructure, in places that could be adversely affected by the hazards and vulnerability is the sensitivity to the hazard and lack of capacity to cope and adapt (Table 1).

Weather and climate hazards in the 2040s are quantified as anomalies in mean temperature and precipitation, coupled with frequency of extreme events. Daily maximum and minimum air temperature and precipitation projections from the World Research Climate Program's CMIP5 are used to project future hazards for RCP 8.5 scenario. Ten global climate models, Australian Community Climate and Earth System Simulator (ACCESS1-0), Beijing Climate Center Climate System Model (BCC-CSM1-1), Community Climate System Model Version 4 (CCSM4), Centro Euro-Mediterraneo sui Cambiamenti Climatici Climate (CMCC-CM), Flexible Global Ocean-AtmosphereLand System Model Grid-point Version 2 (FGOALS-g2), Geophysical Fluid Dynamics Laboratory Earth System Models (GFDL-ESM2M), Institut Pierre Simon Laplace Climate Model 5A, Low-Resolution (IPSL-CM5A-LR), Norwegian Earth System Model (NorESM1-M), Meteorological Research Institute Coupled Global Climate Model Version 3 (MRI-CGCM3), and Max Planck Institute for Meteorology Earth System Model Mixed Resolution (MPI-ESM-MR), dynamically downscaled to $4 \mathrm{~km}$ (Li and Bou-Zeid 2013), are used to project future weather and climate hazards. Data processing is performed in $\mathrm{R}$ and ArcMap 10.3.1 to calculate the daily minimum and maximum temperature and precipitation of each model as the spatial mean for counties in the United

Table 1 The variables used to quantify hazard, exposure, and vulnerability components of climate risk

\section{Hazard}

Temperature change

Precipitation change

Extreme precipitation

Extreme cold

Heat wave

Dry condition

Exposure

Impervious surface

Population

Housing density

Low-lying infrastructure

Vulnerability

Elderly population

Infant population

Farming jobs

Forestry and fishery jobs

Personal income per capita

African American (non-Hispanic)

Hispanic
Mean temperature in the 2040 s compared to baseline temperature

Mean precipitation in the 2040 s compared to baseline precipitation

Days exceeding 98th percentile of daily baseline precipitation

Days below 2 percentiles of the minimum baseline temperature

Days exceeding the 97.5 percentile of daily maximum baseline temperature for 3 consecutive days

Standard precipitation index: standardized z score of monthly precipitation in the 2040 s compared to baseline

EPA's ICLUS

EPA's ICLUS

EPA's ICLUS

Houses and roads $<0.6 \mathrm{~m}$ sea level rise and/or storm surges using surging seas

Woods and Poole (2009)

Woods and Poole (2009)

Woods and Poole (2009)

Woods and Poole (2009)

Woods and Poole (2009)

Woods and Poole (2009)

Woods and Poole (2009) 
States. The daily minimum and maximum temperature and precipitation of each county are calculated for individual models for the ten-year period (2040-2049). Similarly, historic baseline temperature and precipitation are calculated for counties in the United States by aggregating the $1 \mathrm{~km}$ Daymet gridded temperature and precipitation (Thornton et al. 2018) to county level from 1981 to 2010 .

The anomalies in temperature and precipitation and frequency of extreme events in the 2040s are calculated for individual models. Changes in mean temperature and precipitation for the decade (2040s) compared to the historic baseline period are calculated. An extreme temperature event (defined as a heat wave) is calculated as the number of events exceeding the 97.5th percentile of daily maximum baseline temperature for three consecutive days in the 2040s (Anderson and Bell 2011; Kyselý et al. 2011; Zacharias et al. 2014). Cold events are calculated as the number of days in the 2040s below 2 percentiles of the minimum temperature in the baseline period. Extreme precipitation events were calculated as the number of days in the 2040s exceeding 98th percentile of daily baseline precipitation. Similarly, dry conditions are quantified using the monthly standard precipitation index (SPI), which is the standardized $\mathrm{z}$ score of monthly precipitation in the 2040s compared to the historic baseline precipitation. Low SPI values indicate drier conditions, whereas higher SPI values indicate wetter conditions. To capture drier conditions, we averaged the SPI for each month over a ten-years period and extracted the minimum average SPI value. A negative SPI indicates drought condition; however, to build the hazard index, the SPI values are reversed so that high SPI values represent high hazard.

The climate anomalies and extreme events over the 10-year period 2040-2049 are averaged for the ten individual models to calculate the average frequency. Changes in mean temperature, precipitation, extreme precipitation days, heat waves, cold spells, and SPI are rescaled to 0 to 1 (Eq. 1):

$$
X=(x-\min (x)) /(\max (x)-\min (x))
$$

The rescaled variables are summed, and divided by number of hazard components to obtain the weather and climate hazard index for the 2040s (Eq. 2):

$$
\mathrm{H}(0,1)=\sum X_{\mathrm{H}, \mathrm{i}}(0,1) / k
$$

where $\mathrm{H}$ is the hazard index, $\mathrm{X}_{\mathrm{H}}, \mathrm{i}$ is the ith normalized hazard variable, $\sum$ indicates the summation from $i=0$ to $\mathrm{k}$ and $\mathrm{k}$ is the number of metrics.

We quantify exposure with projections of impervious surface, population, and housing density in the 2040s and houses and roads exposed to $0.6 \mathrm{~m}$ ( 2 feet) sea level rise and/ or storm surges. The population, housing density, and impervious surface projections are obtained from the United States Environmental Protection Agency's Integrated Climate and Land-Use Scenarios (ICLUS) projection that are based on the IPCC's A2 (medium-high to high emission) scenario, comparable to RCP 8.5 (EPA 2009). Sea level rise in the United States is likely to be higher than the projected global sea level rise of $0.15-0.38 \mathrm{~m}$ by 2050 (Sweet et al. 2017a). The U.S. Interagency sea level rise task force revised global mean sea level rise scenarios for the United States, project $0.63 \mathrm{~m}$ sea level rise by 2050 under the extreme scenario, also known as physically possible "worst case" scenario (Sweet et al. $2017 \mathrm{~b}$ ). Hence, we used $0.6 \mathrm{~m}$ ( 2 feet) sea level rise to derive the infrastructure exposure in the 2040s using an online tool, called surging seas (Climate Central 2014). Again, the individual metrics are rescaled to 0 to 1 (Eq. 1), summed and divided by the number of metrics to obtain the exposure index E (Eq. 3) 


$$
\mathrm{E}(0,1)=\sum X_{\mathrm{E}, \mathrm{i}}(0,1) / k
$$

where $\mathrm{E}$ is the exposure index, $X_{\mathrm{E}, \mathrm{i}}$ is the ith normalized exposure variable, $\sum$ indicates the summation from $i=0$ to $\mathrm{k}$ and $\mathrm{k}$ is the number of metrics.

We quantify vulnerability using socioeconomic projections of vulnerable populations using Woods and Poole projections (Woods and Poole 2009). Woods and Poole's demographic projections are "cohort component projections" based on fertility and mortality in each county. The economic projections are based on an "Export-Base" model. Both are basically "business-as-usual" projections. The RCP 8.5 and SRES A2, mid-high scenario broadly comparable to RCP 8.5 , define the hazard and exposure projections, respectively. Thus, our projections of hazard, exposure, and vulnerability are in reasonable harmony for near future projections of the 2040s. The socially isolated populations of elderly and infant populations, farming population, natural resource-dependent populations of forestry and fishery, and personal income per capita, racial/ethnic minorities. African American and Hispanic population are rescaled to 0 to 1 (Eq. 1) and summed and divided by the number of components to obtain the vulnerability index V for the 2040s (Eq. 4)

$$
\mathrm{V}(0,1)=\sum X_{\mathrm{V}, \mathrm{i}}(0,1) / k
$$

where $\mathrm{V}$ is the vulnerability index, $\mathrm{X}_{\mathrm{V}, \mathrm{i}}$ is the ith normalized vulnerability variable, $\sum$ indicates the summation from $\mathrm{i}=0$ to $\mathrm{k}$ and $\mathrm{k}$ is the number of metrics.

The future hazard, exposure and vulnerability indices are combined to derive a composite index of climate risk in the 2040s. In our coupling, we assign equal weights to each of our risk components and combine them through multiplication (Eq. 5).

$$
R=H \times E \times V
$$

where $\mathrm{R}$ is the risk index and $\mathrm{H}, \mathrm{E}$ and $\mathrm{V}$ are the hazard, exposure and vulnerability indices, respectively. As any of the individual component indices approach zero, risk approaches zero. As hazard, exposure and vulnerability approach their individual maxima, risk increases with $\mathrm{R}$ approaching a maximum value of 1 .

\section{Results}

We find Florida, California, the central Gulf Coast and North Atlantic to be at highest risk to climate change in the 2040s (Fig. 2). Florida is projected to be equally hard hit by the three components of climate risk: vulnerability, exposure, and climate hazards. Projected frequent heat waves, and extreme precipitation contribute to increased climate hazard in Florida and Gulf Coast counties (SI Figs. 5, 6, 7) even though the overall hazard index is only moderately high relative to other counties with an extreme hazard index (Fig. 3). A recent study by Raymond et al. (2020) noted that the Gulf Coast region has frequently surpassed the heat-humidity habitable limits and our findings further reinforce that in future heat waves will be more common in the region. The concentration of population and infrastructure in urban counties and coastal areas increase exposure (Fig. 4). Similarly, vulnerability in Florida is driven by a high elderly population (Fig. 5) as elderly populations suffering from chronic illness often have limited mobility, diminished sensory awareness, and are socially isolated, all which interfere with their ability to cope with climate hazards, 

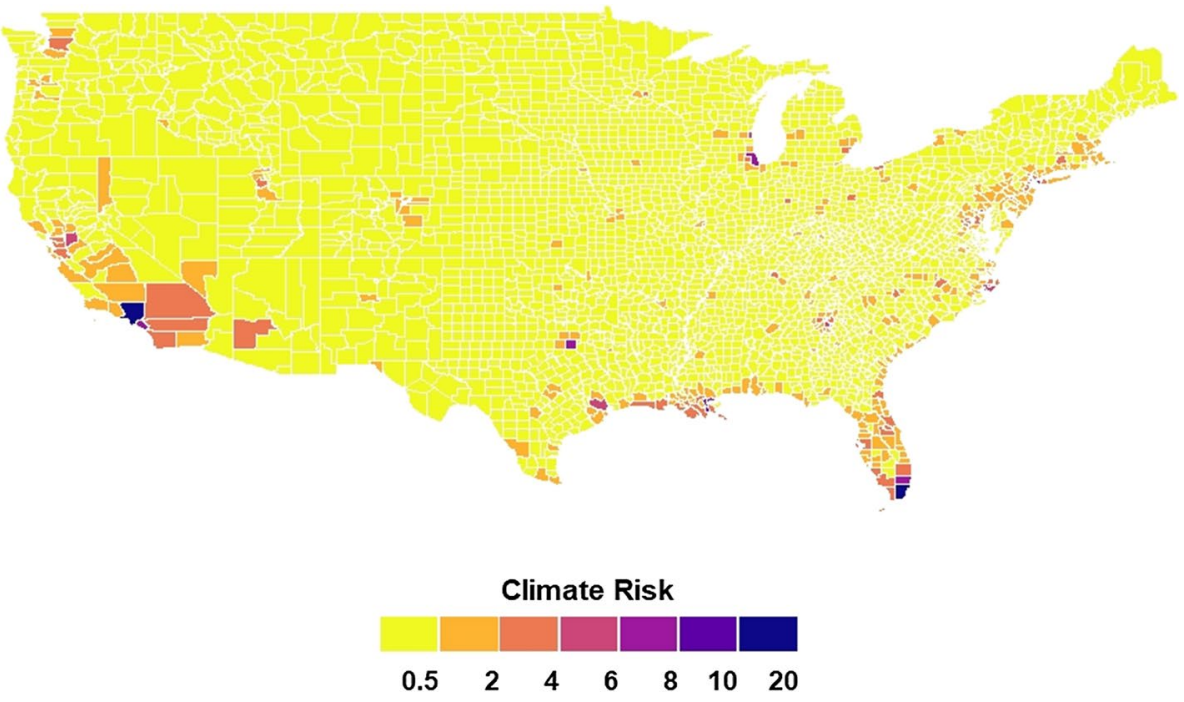

Fig. 2 Climate risk in the 2040s. Indices of climate hazard, exposure, and vulnerability of Figs. 3, 4 and 5 , respectively, are multiplied to derive the climate risk index. Orange, red, and darker colors indicate high climate risk counties. The risk index is highly skewed to the right. The risk index is multiplied by 100 for clarity
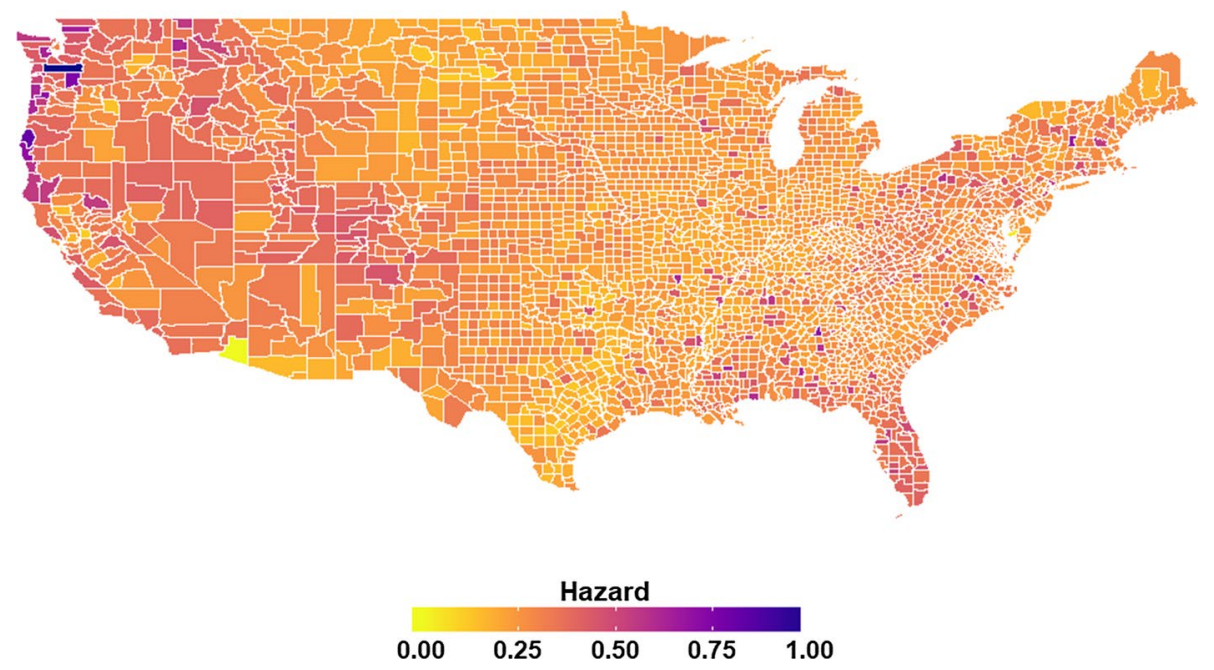

Fig. 3 Climate hazard in the 2040s obtained by merging the anomalies in temperature and precipitation and extreme events measured as-heat wave, cold spells, dry conditions, and extreme precipitation days (see Methods). The hazard index is rescaled 0 to 1

prepare for disasters, and respond during emergency evacuations (Aldrich and Benson 2008; O’Neill and Ebi 2009; Maier et al. 2014).

The coastal counties in the Gulf states of Louisiana, Texas, Mississippi, and Alabama, are at high climate risk (Fig. 2) due to exposure of infrastructure, population, and wealth to 

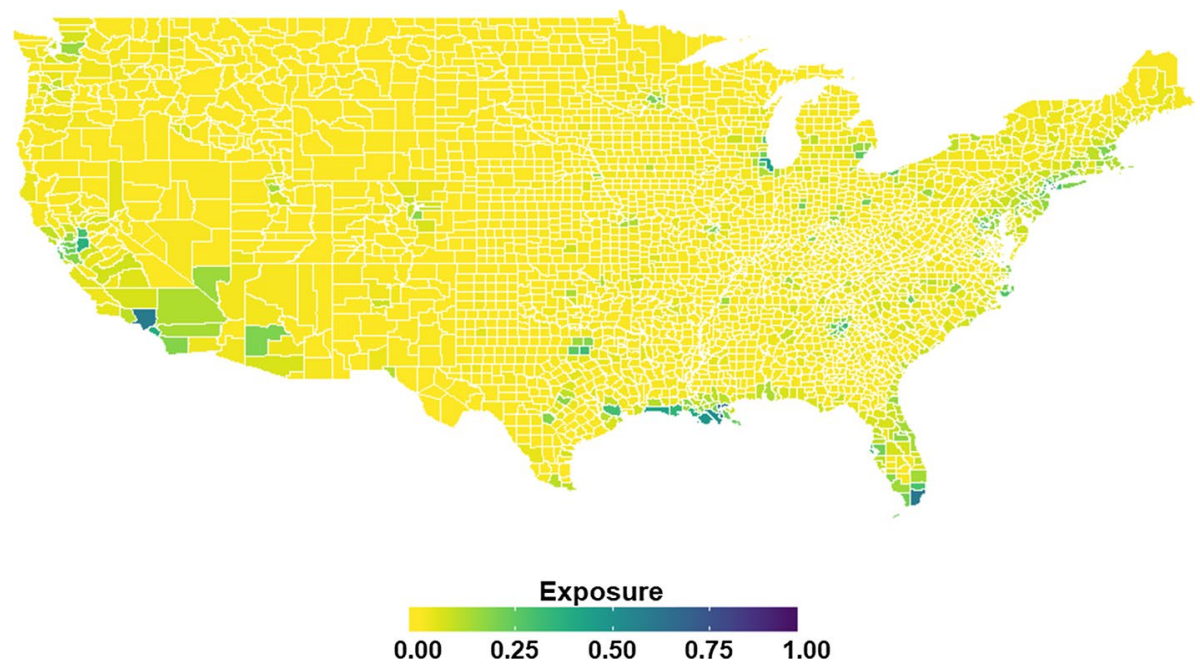

Fig. 4 Population and infrastructure exposure in the 2040s. Impervious surface, population and housing density in 2040s are combined with the infrastructure and homes inundated by $0.6 \mathrm{~m}$ ( 2 feet) sea level rise. Exposure index is rescaled 0 to 1
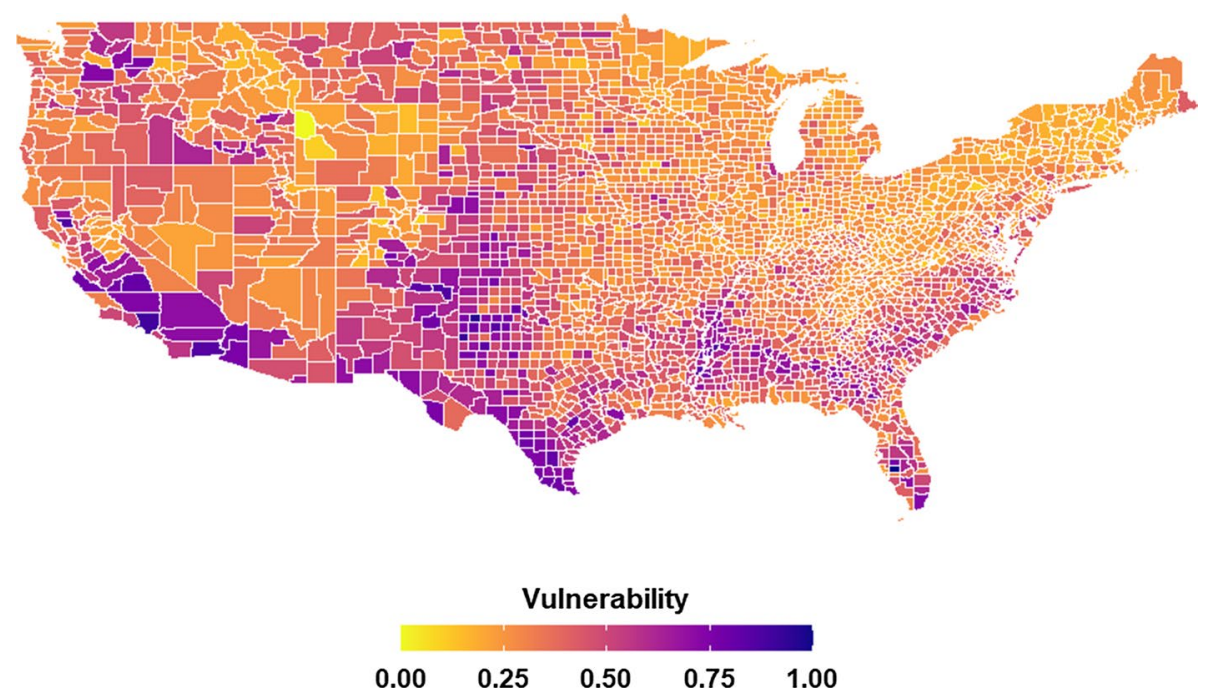

Fig. 5 Socioeconomic vulnerability in 2040. Socioeconomic variables are merged to obtain the vulnerability of the population in 2040. Vulnerability index is rescaled 0 to 1

sea level rise and storm surges coupled with climate hazards such as frequent heat waves (SI Fig. 3). Cold spells and extreme precipitation are projected for the Pacific Northwest (SI Figs. 4, 5). While cold spells are not new to the Pacific Northwest region, for example, the cold spell of 2002 that had adverse economic and ecological consequences (Knapp and Soulé 2005), the National Climate Assessment (May et al. 2018) projects increase 
in temperature and decrease in snow cover in the region, which could mean decrease in cold spells. Therefore, the reason behind projected increase in cold spells in the Pacific Northwest is beyond the scope of this paper and warrants further research. Furthermore, the unique topography of the Cascade Range in the Pacific Northwest triggers more landslides during extreme precipitation events (Henn et al. 2015). High exposure (Fig. 3) and vulnerability (Fig. 4) alone drive high climate risk in California counties (Fig. 2). Although our model shows low hazard index in California, the hazard could be higher in this region in future as the warmer and drier conditions provide fuel to wildfire events (SI Figs. 1, 2). However, our hazard projections do not include wildfire risk as the SPI index is not a proxy or indicator for areas burned by wildfire. Non-coastal Southern California will be vulnerable because of populations that are highly dependent on farming for their livelihood. These farming communities will be highly sensitive to projected warmer and drier conditions. Although the climate hazard is relatively low in these and other Southern California counties (Fig. 3), high vulnerability along with exposure in urban and coastal areas puts these counties at high climate risk in the future. In contrast, the climatologically hazardous counties in the western US (Southern Rocky Mountains and Intermountain West (Fig. 3) with moderate vulnerability (Fig. 5) will have low climate risk due low exposure (Fig. 4).

The Southeast region is projected to have a cooler and wetter climate based on decadal anomalies in temperature and precipitation. Despite the generally cooler and wetter conditions, frequent heat waves make the Southeast more climatologically hazardous than the Midwest with a projected drier climate (SI Figs. 1, 2, 3). Overall climate risk is also high in the Midwestern counties (Fig. 2). The Midwest, which is the farming "powerhouse" of the country, is potentially prone to flood as indicated by frequent extreme precipitation days (SI Fig. 5) which is in alignment with the Fourth National Climate Assessment (Wehner et al. 2017). These precipitation events could hard hit small farming communities in the Midwest. Portions of the North Atlantic-New England region are at moderate risk (Fig. 2) primarily due to warmer conditions (SI Fig. 1) and exposure in coastal counties (Fig. 4). Moreover, the warmer conditions in the North Atlantic and Norwest, particularly Northern Rockies will lead to warming of stream water and lake and increase evaporation and reduced lake level of high-altitude lakes which could potentially decrease trout and salmonids population (Flebbe et al. 2006; Schindler and Bruce 2012). The wetter conditions in the Eastern United States and far Northwest counties (SI Fig. 2) accompanied by frequent extreme precipitation events (SI Fig. 5) could lead to increase in stream flow and could potentially harm the cold-water fish by depositing sediment loads and degrade water quality. Additionally, densely built areas in these regions (SI Fig. 7) fragment the streams, the habitat of cold-water fish (Schindler and Bruce 2012). The Northeast United States is also prone to flood indicated by extreme precipitation days (SI Fig. 5). The flooding events, such as the one brought by hurricane Sandy, can be devastating in the population centers of Northeast, due to massive infrastructures failures. It is important to note that the climate projections themselves don't specifically account for hurricanes. Extreme precipitation days are a proxy for potential flood events associated with the heavy rainfall that hurricanes can bring. However, depending on the topography, floods may occur only when there are consecutive extreme precipitation days."

At present, the Southeast, mostly the Gulf Coast region, suffers the most economic loss to weather and climate-related disasters in the country with contributions from drought, flood, freeze, and tropical storms from 1980 to 2019 according to NOAA (NOAA 2019). In the 2040s, we find that counties in Florida and California (especially Miami-Dade and Los Angeles counties, respectively), along with the coastal counties of Louisiana, Mississippi, Alabama and Texas and major urban centers across the US are the most climatologically 
risk prone areas (Fig. 2). One of the most socially vulnerable regions in the Southeast is the "Black Belt," where the African American population exceeds national averages. This southern sub-region includes a band of rural counties stretching from southern Virginia to east Texas (McDaniel and Casanova 2003; Wimberley and Morris 1997). Despite high social vulnerability in this area, the Southeast region as a whole, except for some coastal areas in the Gulf Coast and Florida, does not rank high in climate risk in the 2040s. This is likely in part due to the fact that the climate projections do not explicitly consider hurricanes. Rather there is a projected regional shift to the West Coast (primarily southern California), with smaller regions in the Southeast (Florida and coastal Louisiana) still at high risk. This shift is a consequence of projected changes in climate hazards and vulnerability (Figs. 3 and 5, respectively). The projected West Coast shift in climate hazards includes the Pacific Northwest (Fig. 3), but without projected high exposure (Fig. 4) or vulnerability (Fig. 5), future climate risk for the region is comparatively moderate (Fig. 2). King County (Seattle) with higher exposure and vulnerability is something of an exception to this general pattern.

\section{Conclusions}

We find both rural and urban counties are at future risk. However, for a climate hazard, the mechanism through which its impacts are felt depends on whether the community is urban or rural. The future risk in urban counties is primarily attributable to high exposure, while in rural counties the risk is a consequence of vulnerability. In urban counties, a single hazard event can cause cascading effects through infrastructure failure, which may not be the case in rural counties. In rural counties, the hazards impact the livelihood of people through loss of lives, crops, and property, and rural counties are usually low in adaptive capacity. More and more populations are projected to migrate to urban areas in the 2040s (Jones et al. 2015; Jones and O'Neill BC 2013). The surge of urban population due to migration will be accompanied by increased impervious surface in the future, as seen in Atlanta and Denver, to meet the infrastructure demands (SI Fig. 7). Increased impervious surface amplifies the climate hazards due to increase in runoff and urban heat island effect exacerbating heat wave conditions (Basara et al. 2010; Tan et al. 2010; Zhao et al. 2018; Li and Bou-Zeid 2013). Despite relatively low climate hazards, urban counties of the Atlanta, New York, Boston, Chicago, Dallas, Houston, and Detroit metropolitan areas will have cascading effects due to high exposure, and hence have high climatic risk in the future (Figs. 2-5). The coastal counties in some of these metropolitan areas are at the brink of damaging sea level rise and storm surges which puts vast wealth, infrastructure, and lives at risk.

Our vulnerability proxy included projections of socio-demographic variables, which are important for understanding general categories of vulnerable populations, for example, racial/ethnic minorities and age-related factors. However, these data do not account for another critical indicator of vulnerability, security of homeownership. This issue differs from the exposure problem of housing density or location discussed in this paper. Neither does it relate to renter versus homeowner status but rather to the security of titles associated with homeownership. When families own homes as a collective or as "tenants in common," this means that the home is owned by multiple, unnamed or informally documented heirs (Johnson Gaither et al. 2019). In these cases, it can be very difficult or perhaps impossible for families devastated by natural disasters to qualify for federal or state 
funding to rebuild their homes. This problem became apparent in the aftermath of Hurricane Katrina on the Gulf Coast in the early 2000s when people affected by the storm tried to apply for the federal government's Road Home program (Kluckow 2014). Initially, many were denied funding because they could not substantiate their ownership of affected properties. Subsequent vulnerability analyses should account for the problem of tenuous land and homeownership, as this factor represents a more precise indicator of the vulnerabilities faced by people in the post-disaster recovery phase.

Future, climate risk varies geographically irrespective of urban-rural settings and the components of climate risk vary by region. Based on the projections used here, future vulnerability is the most dominant component of climate risk in California, while in coastal counties in Louisiana exposure is the most dominating component. Much of the western interior United States is hazard prone (primarily to increase in mean temperature and precipitation), but future exposure is projected to be low and consequently risk is moderated. In Florida counties, all three components of exposure, vulnerability, and hazards dominate. Many of the areas in the United States currently at risk to climate hazards remain so in this relatively new future (2040s). However, our projections also point to increased moderate to high risk in the Pacific Northwest.

As recognized by the turn toward a risk framework for considering the consequences of present and future climate change (e.g., IPCC 2014), a comprehensive characterization of future climate risks requires attention to each of the components of climate risk: hazard, exposure, and vulnerability. Moreover, the components of risk are themselves combinations of multiple factors: multiple and diverse hazards, exposure of various and multiple assets, and differential vulnerability of different subpopulations. Our risk index approach allows for combining multiple factors and components into an integrated characterization of future climate risk. As climate projections are updated, as new hazards are identified, additional assets are found to be exposed to these hazards, and new vulnerabilities are identified, they can be readily integrated into this framework. Our multi-component approach, a first for the entire contiguous US at the county level, can help planners develop state, regional and national adaptation strategies to target counties that will be hit by multiple hazards, future hazard-prone counties, and vulnerable and exposed populations in an integrated evaluation of future risk to climate change.

We reiterate that multiple hazards may be in the form of compound events which occur at the same time or in rapid succession (Kopp et al. 2017) or the same location may be subject to different hazards at different times. Portions of Texas, for example, may experience extreme drought in some years and extreme precipitation in others, similarly in California. Addressing the co-occurrence could be an avenue for future study by introducing synchronicity factors into the equation based on whether events were occurring at the same time or in sequence.

Furthermore, our climate risk provides equal weights to the individual climate hazards. The impact of disaster events translates in terms of loss of lives accompanied by economic loss. It is very challenging to determine the balance point between economic loss and loss of lives or species diversity for a given event and provide weights accordingly. This is a subject for further research and analysis. We derived a climate risk index based on SRES A2 and RCP 8.5 scenarios for exposure and hazard, respectively. The high emission scenario was selected based on the assumption that these nominally "high" scenarios are unlikely to significantly diverge from "business-as-usual" before 2050. By using RCP8.5 scenario, we are not suggesting "RCP8.5" as the "business as usual" scenario, and we do acknowledge that RCP2.6 and RCP4.5 scenarios are equally important for comparative study. 
The historical to future climate anomalies are calculated as differences between the GCM projections and historical observations from Daymet data. Ashfaq et al. (2016), source of the dynamically downscaled GCM projections, concluded that overall, their simulations provide a comprehensive and detailed understanding of the potential changes in climate for the US. This conclusion came in part from their comparison of historical simulations with Daymet data in which biases were modest. We accordingly believe that use of the Daymet historical data as the historical baseline is justified as generating one potential future climate change. Use of the historical GCM simulations as the baseline for the climate change projections would generate another potential future. Our risk assessment is for only one potential future. Examination of the sensitivity of our risk assessment methodology to alternative future climate change is worthy of future research.

Open Access This article is licensed under a Creative Commons Attribution 4.0 International License, which permits use, sharing, adaptation, distribution and reproduction in any medium or format, as long as you give appropriate credit to the original author(s) and the source, provide a link to the Creative Commons licence, and indicate if changes were made. The images or other third party material in this article are included in the article's Creative Commons licence, unless indicated otherwise in a credit line to the material. If material is not included in the article's Creative Commons licence and your intended use is not permitted by statutory regulation or exceeds the permitted use, you will need to obtain permission directly from the copyright holder. To view a copy of this licence, visit http://creativecommons.org/licenses/by/4.0/.

\section{References}

Aldrich N, Benson WF (2008) Peer reviewed: disaster preparedness and the chronic disease needs of vulnerable older adults. Prev Chronic Dis 5:A27

Anderson GB, Bell ML (2011) Heat waves in the United States: Mortality risk during heat waves and effect modification by heat wave characteristics in 43 U.S. communities. Environ Health Persp 119:210-218

Ashfaq M, Rastogi D, Mei R, Kao S-C, Gangrade S, Naz BS, Touma D (2016) High-resolution ensemble projections of near-term regional climate over the continental United States. J Geophys Res Atmos 121:9943-9963

Baum S, Horton S, Choy DL (2008) Local urban communities and extreme weather events: Mapping social vulnerability to flood. Australas J Reg Stud 14(3):251

Basara JB, Basara HG, Illston BG, Crawford KC (2010) The impact of the urban heat island during an intense heat wave in Oklahoma City. Adv Meteor 2010:230365

Climate Central (2014) Surging Seas Risk Finder: Sea Level Rise and Coastal Flood Exposure. https://seale vel.climatecentral.org/.

Emrich CT, Cutter SL (2011) Social vulnerability to climate-sensitive hazards in the Southern United States. Weather Clim Soc 3:193-208

Flebbe PA, Roghair LD, Bruggink JL (2006) Spatial modeling to project southern Appalachian trout distribution in a warmer climate. Trans Am Fish Soc 135(5):1371-1382

Frans C, Istanbulluoglu E, Lettenmaier DP, Fountain AG, Riedel J (2018) Glacier recession and the response of summer streamflow in the Pacific Northwest United States, 1960-2099. Water Resour Res 54(9):6202-6225

Hall MH, Fagre DB (2003) Modeled climate-induced glacier change in Glacier National Park, 1850-2100. Bioscience 53(2):131-140

Henn B, Cao Q, Lettenmaier DP, Magirl CS, Mass C, Bower BJ, Laurent MS, Mao Y, Perica S (2015) Hydroclimatic conditions preceding the March 2014 Oso landslide. J Hydrometeorol 16(3):1243-1249

Hauer ME, Evans JM, Mishra DR (2016) Millions projected to be at risk from sea- level rise in the continental United States. Nat Clim Chang 6:691-695

IPCC (2014) Summary for policymakers In: Field CB et al (eds) Climate Change 2014: Impacts, Adaptation, and Vulnerability. Part A: Global and Sectoral Aspects. Contribution of Working Group II to the Fifth Assessment Report of the Intergovernmental Panel on Climate Change, Cambridge University Press, Cambridge, and New York, pp 1-32 
Jay A, Reidmiller DR, Avery CW, Barrie D, DeAngelo BJ, Dave A, Dzaugis M, Kolian M, Lewis KLM, Reeves K, Winner D (2018) Overview In Impacts, Risks, and Adaptation in the United States: Fourth National Climate Assessment, Volume II (Reidmiller DR, Avery CW, Easterling DR, Kunkel KE, Lewis KLM, Maycock TK, Stewart BC (eds.) U.S. Global Change Research Program, Washington, DC, USA, pp. 33-71. https://doi.org/10.7930/NCA4.2018.CH1.

Johnson Gaither C, Carpenter A, McCurty TL, Toering S (2019) Heirs' Property in the South: Fostering Stable Ownership to Prevent Land Loss and Abandonment. e-General Technical Report, SRS-244, September 2019. USDA Forest Service, Southern Research Station. https://www.fs.usda.gov/trees earch/pubs/58543.

Jones B, O’Neill BC, McDaniel L, McGinnis S, Mearns LO, Tebaldi C (2015) Future population exposure to US heat extremes. Nat Clim Chang 5:652-655

Jones B, O’Neill BC (2013) Historically grounded spatial population projections for the continental United States. Environ Res Lett 8:044021

Karl TR, Meehl GA, Miller CD, Murray WL (2008) Weather and Climate Extremes in a Changing Climate. Regions of Focus: North America, Hawaii, Caribbean, and US Pacific Islands In: Karl TR et al (eds) A Report by the US Climate Change Science Program and the Subcommittee on Global Change Research, Washington, DC, USA, pp. 1-9

KC B, Shepherd JM, Johnson-Gaither C (2015) Climate change vulnerability assessment in Georgia. Appl Geogr 371:62-74

Kluckow R (2014). The Impact of heir property on post-Katrina housing recovery in New Orleans. https:// doi.org/10.13140/RG.2.2.13565.97767

Kuczynski L, Chevalier M, Laffaille P, Legrand M, Grenouillet G (2017) Indirect effect of temperature on fish population abundances through phenological changes. PLoS ONE 12(4):e0175735

Kyselý J, Plavcová E, Davídkovová H, Kyncl J (2011) Comparison of hot and cold spell effects on cardiovascular mortality in individual population groups in the Czech Republic. Clim Res 49:113-129

Kopp RE, Hayhoe K, Easterling DR, Hall T, Horton R, Kunkel KE, LeGrande AN (2017) Potential surprises - compound extremes and tipping elements. In: Wuebbles DJ et al (eds) Climate Science Special Report: Fourth National Climate Assessment. US Global Change Research Program Washington DC, USA, pp 411-429

Knapp PA, Soulé PT (2005) Impacts of an extreme early-season freeze event in the interior Pacific Northwest (30 October-3 November 2002) on western juniper woodlands. J Appl Meteorol 44(7):1152-1158

Li D, Bou-Zeid E (2013) Synergistic interactions between urban heat islands and heat waves: The impact in cities is larger than the sum of its parts. J Appl Meteorol Clim 52:2051-2064

Maier G, Grundstein A, Jang W, Li C, Naeher LP, Shepherd M (2014) Assessing the performance of a vulnerability index during oppressive heat across Georgia, United States. Weather Clim Soc 6:253-263

May C, Luce C, Casola J, Chang M, Cuhaciyan J, Dalton M, Lowe S, Morishima G, Mote P, Petersen A, Roesch-McNally G, York E (2018) Northwest. In: Reidmiller DR et al (eds) Impacts, risks, and adaptation in the united states: fourth national climate assessment, vol II. U.S. Global Change Research Program, Washington, DC, pp 1036-1100

McDaniel J, Casanova V (2003) Pines in lines: tree planting, H2B guest workers, and rural poverty in Alabama. J Rural Soc Sci 19(1):4

Nicholls RJ, Wong PP, Burkett V, Woodroffe CD, Hay J (2008) Climate change and coastal vulnerability assessment: scenarios for integrated assessment. Sustainability Sci 3:89-102

NOAA (2019) National Centers for Environmental Information (NCEI) U.S. Billion-Dollar Weather and Climate Disasters. https://www.ncdc.noaa.gov/billions.

Nunez S, Arets E, Alkemade R, Verwer C, Leemans R (2019) Assessing the impacts of climate change on biodiversity: is below $2^{\circ} \mathrm{C}$ enough? Climatic Change 154(3-4):351-365

O’Neill MS, Ebi KL (2009) Temperature extremes and health: Impacts of climate variability and change in the United States. J Occup Environ Med 51:13-25

Rasche L, Fahse L, Bugmann H (2013) Key factors affecting the future provision of tree-based forest ecosystem goods and services. Climatic Change 118(3-4):579-593

Raymond C, Matthews T, Horton RM (2020) The emergence of heat and humidity too severe for human tolerance. Sci Adv 6(19): 1838

Reams MA, Lam NSN, Baker A (2012) Measuring capacity for resilience among coastal counties of the U.S. Northern Gulf of Mexico Region. Am J Clim Change 1:194-204

Rijnsdorp AD, Peck MA, Engelhard GH, Möllmann C, Pinnegar JK (2009) Resolving the effect of climate change on fish populations. ICES J Mar Sci 66:1570-1583

Schindler DW, Bruce J (2012) Freshwater resources, Chapter 3. Climate Change Adaptations: A Priorities Plan for Canada 122.

Shepherd M, KC B (2015) Climate change and African Americans in the USA. Geogr Compass 9: 579-591 
Sweet WV, Horton R, Kopp RE, LeGrande AN, Romanou A (2017a) Sea level rise. In: Wuebbles DJ et al (eds) Climate science special report: fourth national climate assessment. US Global Change Research Program Washington DC, USA, pp 333-363

Sweet WV, Kopp RE, Weaver CP, Obeysekera J, Horton RM, Thieler ER, Zervas C (2017b) Global and regional sea level rise scenarios for the United States. National Oceanic and Atmospheric Administration, National Ocean Service, Silver Spring, MD, p 75

Tan J, Zheng Y, Tang X, Guo C, Li L, Song G, Zhen X, Yuan D, Kalkstein AJ, Li F (2010) The urban heat island and its impact on heat waves and human health in Shanghai. Int J Biometeorol 54:75-84

Thornton PE, Thornton MM, Mayer BW, Wei Y, Devarakonda R, Vose RS, Cook RB (2018) Daymet: Daily Surface Weather Data on a 1-km Grid for North America, Version 3. (ORNL DAAC)

Tu CY, Chen KT, Hsieh CH (2018) Fishing and temperature effects on the size structure of exploited fish stocks. Sci Rep 8(1):1-10

US EPA (2009) Land-Use Scenarios: National-Scale Housing-Density Scenarios Consistent with Climate Change Storylines (Final Report) EPA/600/R-08/076F.

Wehner MF, Arnold JR, Knutson T, Kunkel KE, LeGrande AN (2017) Droughts, floods, and wildfires. In: Wuebbles DJ et al (eds) Climate science special report: fourth national climate assessment, vol I. U.S. Global Change Research Program, Washington, DC, USA, pp 231-256. https://doi.org/10.7930/J0CJ8 BNN

Wenger SJ, Isaak DJ, Dunham JB, Fausch KD, Luce CH, Neville HM, Rieman BE, Young MK, Nagel DE, Horan DL, Chandler GL (2011) Role of climate and invasive species in structuring trout distributions in the interior Columbia River Basin, USA. Can J Fish Aquat Sci 68:988-1008

Williams JE, Isaak D, Imhof J, Hendrickson DA, McMillan JR (2015) Cold-water fishes and climate change in North America. Ref Module Earth Sys Environ Sci. https://doi.org/10.1016/B978-0-12-40954 8-9.09505-1

Wimberley RC, Morris LV (1997) The southern black belt: a national perspective. TVA Rural Studies University of Kentucky

Woods and Poole (2009) Complete economic and demographic data source (CEDDS) on CD-ROM technical documentation.

Zacharias S, Koppe C, Mücke H-G (2014) Influence of heat waves on Ischemic heart diseases in Germany. Climate 2:133-152

Zhao L, Oppenheimer M, Zhu Q, Baldwin JW, Ebi KL, Elie Bou-Zeid E, Guan K, Liu X (2018) Interactions between urban heat islands and heat waves. Environ Res Lett 13:034003

Publisher's Note Springer Nature remains neutral with regard to jurisdictional claims in published maps and institutional affiliations. 